\title{
Exploring interaction effects from mechanisms between climate and land-use changes and the projected consequences on biodiversity
}

\author{
Sarahi Nunez ${ }^{1}$ D $\cdot$ Rob Alkemade ${ }^{1,2}$
}

Received: 21 September 2020 / Revised: 2 July 2021 / Accepted: 11 August 2021 /

Published online: 24 August 2021

(C) The Author(s) 2021

\begin{abstract}
Changes in climate and land use are major drivers of biodiversity loss. These drivers likely interact and their mutual effects alter biodiversity. These interaction mechanisms are rarely considered in biodiversity assessments, as only the combined individual effects are reported. In this study, we explored interaction effects from mechanisms that potentially affect biodiversity under climate change. These mechanisms entail that climate-change effects on, for example, species abundance and species' range shifts depend on land-use change. Similarly, land-use change impacts are contingent on climate change. We explored interaction effects from four mechanisms and projected their consequences on biodiversity. These interactions arise if species adapted to modified landscapes (e.g. cropland) differ in their sensitivity to climate change from species adapted to natural landscapes. We verified these interaction effects by performing a systematic literature review and meta-analysis of 42 bioclimatic studies (with different increases in global mean temperature) on species distributions in landscapes with varying cropland levels. We used the Fraction of Remaining Species as the effect-size metric in this meta-analysis. The influence of global mean temperature increase on FRS did not significantly change with different cropland levels. This finding excluded interaction effects between climate and landscapes that are modified by other land uses than cropping. Although we only assessed coarse climate and land-use patterns, global mean temperature increase was a good, significant model predictor for biodiversity decline. This emphasizes the need to analyse interactions between land-use and climate-change effects on biodiversity simultaneously in other modified landscapes. Such analyses should also integrate other conditions, such as spatial location, adaptive capacity and time lags. Understanding all these interaction mechanisms and other conditions will help to better project future biodiversity trends and to develop coping strategies for biodiversity conservation.
\end{abstract}

Keywords Climate change $\cdot$ Cropland $\cdot$ Interactions $\cdot$ Land-use change $\cdot$ Modified landscapes $\cdot$ Species abundance

Communicated by Daniel Sanchez Mata.

Sarahi Nunez

sarahi.nunezramos@wur.nl

Extended author information available on the last page of the article 


\section{Introduction}

Changes in climate and land use are major drivers of biodiversity loss in this century (Sala et al. 2000; Pereira et al. 2010; Tittensor et al. 2014; IPBES 2019). These drivers likely interact and potentially change their mutual effects on biodiversity (Opdam and Wascher 2004; Oliver and Morecroft 2014; Hof 2021). Interaction mechanisms, however, are rarely considered by studies that assess both climate and land-use change impacts on biodiversity (Alkemade et al. 2009; Visconti et al. 2015). Such studies commonly use scenario and model analysis that combine bioclimatic and land-use variables to evaluate species and habitat range changes (e.g. Jetz et al. 2007; Pompe et al. 2008; Asner et al. 2010; Beltran et al. 2014; Brown et al. 2015; Byrd et al. 2015; Garcia-Valdes et al. 2015; Jantz et al. 2015; Rondinini and Visconti 2015; Visconti et al. 2015; Newbold 2018). Other studies use models that spatially overlay the individual effects solely showing combined or additive effects (e.g. Broennimann et al. 2006; Thuiller et al. 2006a; Mantyka-Pringle et al. 2012).

Interaction effects occur when two independent variables together have a larger (or lesser) effect on a dependent variable than the effects expected from the independent variables acting individually. Climate and land-use change effects will likely interact in several ways with respect to biodiversity (Brook et al. 2008; Hof 2021). In principle the effect of climate change (e.g. per degree of global mean temperature increase) on biodiversity depends on land-use change (e.g. per hectare of habitat converted to agriculture), and similarly the land-use change impact is contingent on climate change (Oliver and Morecroft 2014). The expected interaction effects will likely include changes in species' fundamental niches, the degree of species' range shifts and adaptive population responses (Sales et al. 2020; Latimer and Zuckerberg 2021).

Oliver and Morecroft (2014) described possible interaction mechanisms between climate and land-use change effects. Interaction effects, for example, indicate that species in heavily modified landscapes may respond differently to climate change (i.e. they have higher sensitivity levels) than species in pristine landscapes. Modified landscapes include fragmented or converted areas that reduce available species' habitats and increase distances between remaining habitat patches (Fahrig 2003). These interactions mechanisms, however, are poorly understood due to limited data availability and methodological constraints (Brook et al. 2008; de Chazal and Rounsevell 2009; Hof 2021).

Under climate change, species shift their geographical ranges to find suitable climate. For some species, the new climate envelope may overlap with the old one (Vos et al. 2008). This depends on the time span and intensity of climate change, but also multiple new land uses influence the species' response to climate change (Hannah et al. 2007; Bellard et al. 2012). Such land-use change include fragmented or converted land that likely constitutes a land barrier for species dispersal. A thorough understanding of species' dispersal under projected land-use and climate changes is missing (Wiens et al. 2009; Hof 2021). Regardless of species' dispersal being widely acknowledged in projecting geographic distribution of species (Thomas 2000; Guisan and Thuiller 2005; Midgley et al. 2006; Thuiller et al. 2008) how modified habitats hinder dispersal in response to climate change and how do interaction mechanisms arise, is poorly studied.

The primary objective of our study is to explore interaction effects from mechanisms between climate and land-use change. For this purpose, we selected four interaction mechanisms that are described in Oliver and Morecroft (2014). These mechanisms are (i) interactions between demographic factors, (ii) evolutionary trade-offs and synergies which impose selection on populations, (iii) threshold effects of population size on extinction 
risks and (iv) threshold occupancy for meta-population persistence. We identified expected consequences for each mechanism and validated the interactions with evidence from a literature review of studies that used bioclimatic models and climate-change scenarios in modified landscapes. We focused on intensively managed landscapes (i.e. croplands). We estimated the proportion of cropland area from these studies to indicate land use and landuse change. We then performed a meta-analysis and used the Fraction of Remaining Species (FRS) to indicate biodiversity decrease within each study region. FRS is a simple but effective indicator that represents the local response of species to climate change (Nunez et al. 2019). FRS decreases if the climate is not suitable anymore for a species at a location. The interaction mechanisms occur if the FRS in large cropland areas significantly differs from the FRS in areas with small cropland extent. By validating these expected consequences, we achieved a deeper understanding of drivers interactions that can be used in future biodiversity assessments.

\section{Methods}

\section{Interaction mechanisms}

Mechanism 1 describes interactive effects that can affect a number of demographic factors (e.g. birth rates, death rates and immigration/emigration). For example, edge effects may cause habitat desiccation and increased species mortality. This is exacerbated under extreme weather conditions. Mechanism 2 describes the evolutionary trade-offs and synergies where both climate change and land-use change impose selection on populations for more tolerant genotypes (i.e. adaptive capacity). Mechanism 3 describes threshold effects of population size on extinction risks. This is particularly critical for small populations which probably suffer larger extinction risks due to genetic drift, inbreeding depression, inability to find mates and increased susceptibility to environmental uncertainty. Finally, Mechanism 4 describes effects on the threshold occupancy for meta-population persistence. This mechanism shows that when the proportion of patches falls below a threshold level, the extinction of the entire meta-population can rapidly follow. We identified expected consequences that can further elucidate on these interaction mechanisms (Table 1). These expected consequences indicate that species' responses to climate change vary if the landscape changes (i.e. different levels of cropland area).

All four mechanisms mimic ecological processes that result in declining populations if climate and land-use change effects interact upon species. Such processes likely occur in areas with remaining suitable climates. Thus, declining populations can be evidenced with meta-analysis from bioclimatic modelling studies and the FRS indicator. If such location also experiences land-use change, climate-change impacts are likely to increase and species are expected to be more sensitive on average, and thus disappear.

\section{Literature review}

We conducted a literature review to find evidence on the expected consequences of the interaction mechanisms. We queried the ISI Web-of-Science to identify bioclimatic model and scenario studies that (1) assessed the effects of global mean temperature increase on terrestrial species and (2) included cropland as one of the land-use types in their study area. We combined keywords into a search string to conduct the review: [(climat* SAME 


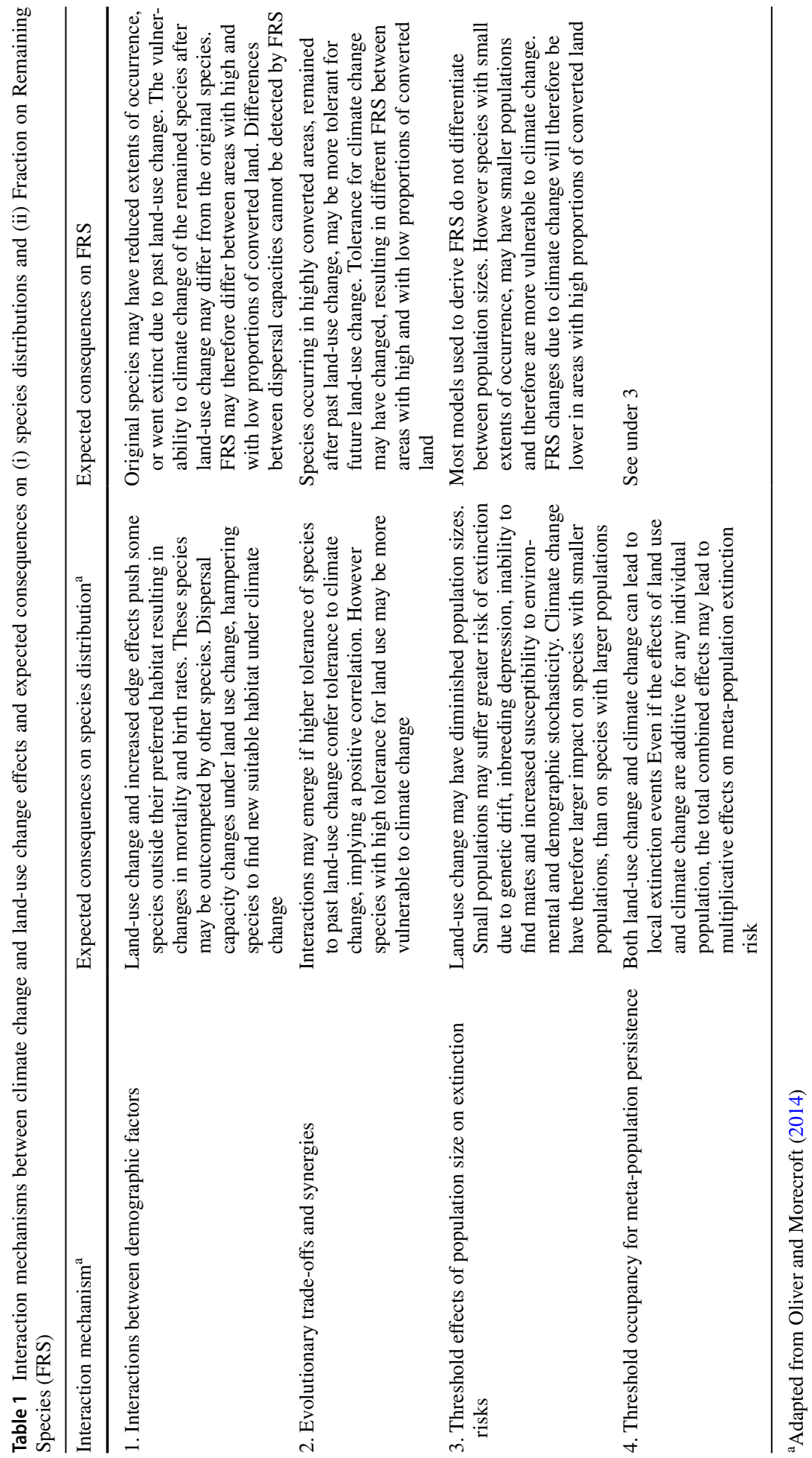


change*) OR (temperature SAME change*) OR (temperature SAME increase) OR (global SAME warming) OR (climat* SAME warming)] AND [(biodiversity) OR (diversity SAME species) OR (species SAME richness*) OR (species SAME distribution*) OR (species SAME abundance*) OR (species SAME occurrence*) OR (species SAME turnover) OR (species SAME loss*) OR (species SAME gain*) OR (species SAME composition) OR (species SAME assemblage*)] AND [(land use SAME change*) OR (fragment* SAME landscape) OR (fragment* SAME habitat*) OR (fragment* SAME habitat SAME connectivity)] AND [(dispersal SAME capacity) OR (species SAME clima** SAME sensitivit*)]. We defined inclusion criteria to determine the relevance of the studies. These criteria request that studies to: (i) present data on species composition (i.e. number of species before and after climate change); (ii) indicate the location of the study area to calculate spatial extent and land-use intensity; (iii) provide information on global temperature increase used in the original analysis, or indicates the type of climate-change scenario and general circulation model used; (iv) indicate the reference and projected years for climate change; and (v) specify the taxonomic groups assessed in the original analysis. We screened studies by title for their relevance to the purpose of our study. Those studies selected were then screened by abstract and, when providing limited information in their abstracts, were fully screened, both in content and supporting material. We consolidated a database from all data extracted from the selected studies to perform meta-analysis on species distributions in landscapes with varying cropland levels. These data included study location, global mean temperature increase $\left({ }^{\circ} \mathrm{C}\right)$, land use/land cover, number of species in the original and the projected climate situations, dispersal capacities, taxonomic group, spatial extent and the spatial resolution. We also qualitative assessed studies on the impact of habitat fragmentation and climate change on species dispersal.

\section{Projected land-use and climate changes}

Land use was indicated by the percentage of cropland in the original study areas. We estimated cropland percentage by using the land-cover maps from the European Space Agency (ESA) Climate Change Initiative (CCI) (Defourny et al. 2014). These are consistent global maps at $300 \mathrm{~m}$ spatial resolution on an annual basis from 1992 to 2015 . We used the year of the original study. We aggregated land-cover categories that indicate intensively managed areas. These categories are: cropland (rainfed), herbaceous cover, cropland (irrigated or post-flooding), mosaic cropland $(>50 \%)$ and mosaic natural vegetation. We used ArcGIS 10.2.1 to estimate the spatial extent of the study sites and the cropland percentage. We also identified other important characteristics of the original study areas, such as study areas located in protected areas, to determine the applied level of change. Land-use change was classified as very low, low, moderate, high and very high. These classes respectively correspond to $0-5 \%, 0-10 \%, 10-15 \%, 15-20 \%$ and $>20 \%$ of cropland (i.e. cropland level) respectively. Climate change in these studies was indicated by their scenario's global mean temperature increase.

\section{Meta-analysis}

We estimated the overall reduction in species abundance in landscapes with varying cropland levels with a mixed-effects meta-analysis. As an effect size, we calculated the FRS. FRS quantifies the remaining proportion of biodiversity compared to the original situation in the selected studies. This also indicates changes in species abundance of the local 
biodiversity. Following Nunez et al. (2019), FRS was calculated as the average of ratios between the number of species in the projected climate situation and the original number of species within each locality in the original study sites (Eq. 1):

$$
F R S=\frac{1}{n} \cdot \sum_{i=1}^{n} \frac{S_{d i}}{S_{o i}}
$$

where $S_{d i}$ is the expected number of species in locality $i$ after climate change and $S$ oi is the number of species in locality $i$ in the original situation. $n$ is the total number of localities.

We used the package 'Metafor' in the R-3.2.2 software (Viechtbauer 2010) and the rma. $m v()$ function assuming independence between the effect size and sampling variance. We built mixed-effects models with random-effects structures to examine variations in the relationship between FRS and both cropland level and global mean temperature increase. We included first-order interaction terms and second-order interaction terms to account for variation in the slope of the relationship between global mean temperature increases and cropland levels. We compared the models using the Bayesian Information Criterion.

\section{Result}

The systematic literature review yielded more than 100 studies that contained relevant titles and abstracts. Of these, 42 studies corresponded to the selected criteria for data extraction (see Electronic Supplementary Material S1: List of selected studies). Some geographical bias was found since most of the studies stemmed from Western Europe (19) or Africa (10), while a few studies from the Americas (7), Oceania (4) and China (2). These studies covered a wide range of temperature increase up to $5{ }^{\circ} \mathrm{C}$. The study taxa included plants, vertebrates (e.g. birds and mammals) and insects (e.g. butterflies). The published years of the selected studies (i.e. 1994-2015) matched the land-cover ESA CCI data. We collated these studies, including 219 effect sizes (see Electronic Supplementary Material S2: Database). These effect sizes corresponded to very low (53), low (54), moderate (31), high (12), and very high (69) cropland levels.

For the meta-analysis, we retained the random-effect structure [1 I Study + 1 | Extent $]$ with the lowest Bayesian Information Criterion (i.e. -197.67) (see Electronic Supplementary Material S3: Results of random effect models). The retained structure contains the unique ID (i.e. 'Study') for each selected study and the spatial extent (i.e. 'Extent') of the study site indicated by the number of pixels. The second order interaction term (i.e. squared global mean temperature increase - cropland level) did not improve the model fit and was therefore dismissed. The final model used was global mean temperature increase +cropland level + global mean temperature increase $\cdot$ cropland level.

The results from the mixed-effects model indicated that global mean temperature increase is a good, significant model predictor for biodiversity decline (i.e. estimate $=-0.0628$ with $95 \%$ confidence interval: -0.0881 to -0.0374 ; Table 2 ). However, the model results did not reveal significant interactions between cropland levels and global mean temperature increases, which indicates that the influence of different cropland levels on FRS did not change with global mean temperature increase (i.e. estimate very low $=-0.0342$ with $95 \%$ confidence interval: -0.2299 to 0.1615 and estimate very high $=-0.0019$ with $95 \%$ confidence interval: -0.0627 to 0.0589 ; Table 2 and Fig. 1 ).

A mixed-effect model using global mean temperature increase as the only predictor variable was significant (Table 3). This suggests that temperature increase strongly influenced 
Table 2 Results of the mixed-random effects model 'global mean temperature increase + cropland level + global mean temperature increase · cropland level' with FRS as response variable

\begin{tabular}{lrlcrll}
\hline Fixed effects & Estimate & SE & $p$-value & $z$-value & CI (lb) & CI (ub) \\
\hline Intercept & 0.0309 & 0.0591 & 0.6009 & 0.5230 & -0.0849 & 0.1467 \\
Temperature $^{\mathrm{a}}$ & -0.0628 & 0.0129 & $<0.0001$ & -4.8506 & -0.0881 & $-0.0374 * * *$ \\
Land use $^{\mathrm{b}}$ & -0.0568 & 0.1026 & 0.5800 & -0.5533 & -0.2579 & 0.1443 \\
$\quad$ Very low & -0.0342 & 0.0998 & 0.732 & -0.3424 & -0.2299 & 0.1615 \\
Low & -0.0783 & 0.1137 & 0.4912 & -0.6885 & -0.3011 & 0.1446 \\
Moderate & 0.0678 & 0.0676 & 0.3165 & 1.0017 & -0.0648 & 0.2003 \\
$\quad$ Very high & -0.0019 & 0.0310 & 0.9510 & -0.0615 & -0.0627 & 0.0589 \\
Temperature: Land use very low & 0.0440 & 0.0293 & 0.1325 & 1.5043 & -0.0133 & 0.1014 \\
Temperature: Land use low & 0.0548 & 0.0385 & 0.1548 & 1.4229 & -0.0207 & 0.1303 \\
Temperature: Land use moderate & 0.0071 & 0.0154 & 0.6461 & 0.4592 & -0.0231 & 0.0372 \\
Temperature: Land use very high & 0.0309 & 0.0591 & 0.6009 & 0.5230 & -0.0849 & 0.1467 \\
\hline
\end{tabular}

${ }^{\mathrm{a}}$ Global mean temperature increase is a predictor variable

${ }^{\mathrm{b}}$ Cropland with the five levels (i.e. very low, low, moderate, high, and very high) is a predictor variable. The land-use level 'high' was used as intercept

Significance codes: 0 ‘*** 0.001 '**’ 0.01 '*’ 0.05 ‘’ 0.1 “ 1

FRS. Contrary, a mixed-effect model using cropland level as the only predictor variable was less significant, which indicates that land use did not influence or the influence was not significant for FRS.

Our analysis of global mean temperature increase indicated a general decrease of FRS. Both estimates for temperature in Tables 2 and 3 resulted in FRS reduced by 14\% (95\% confidence interval: $8 \%$ to $18 \%$ ) and $12 \%$ (95\% confidence interval: $9 \%$ to $15 \%$ ), respectively.

\section{Discussion and conclusions}

Based on the expected consequences for the studied interaction mechanisms, we found that the FRS of areas with a large cropland level (i.e. intensively managed) did not significantly differ from those areas with a low cropland level (i.e. close to pristine, natural areas). This finding excluded interaction effects between global mean temperature increases and landscapes that are modified by other land uses than cropping. We, however, did not find any study that assessed interactions between land-use and climate-change effects. This makes assessing direct interaction mechanisms in other modified landscapes unattainable.

The few studies for mechanism 1 that affected species' dispersal in response to global mean temperature increases and habitat fragmentation, indicated that species' dispersal ability is closely related to the landscape structure and fragmentation level (e.g. Wiens et al. 2009; McGuire et al. 2016) and thus only species with unlimited dispersal capacities can always establish remote populations in fragmented landscapes (Opdam and Wascher 2004). This indicates that increasing landscape fragmentation will likely hinder species' distribution shifts in response to climate change. We did not find any study that quantified climate induced dispersal of species in fragmented landscapes. Most found studies focused on either single impacts of fragmentation (Thomas 2000; Fahrig 2003), climate 
(a) Reference

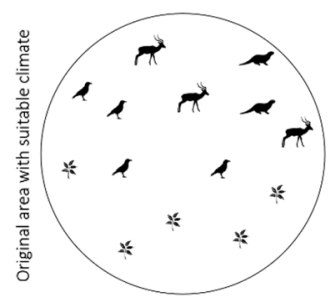

(c) Projected 2

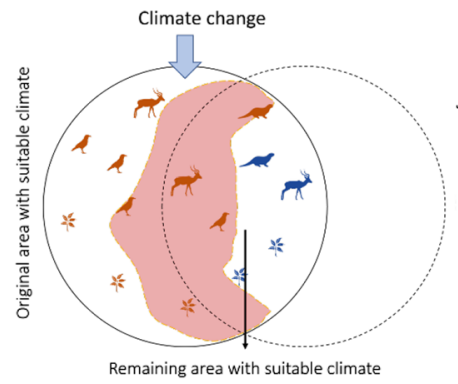

(b) Projected 1

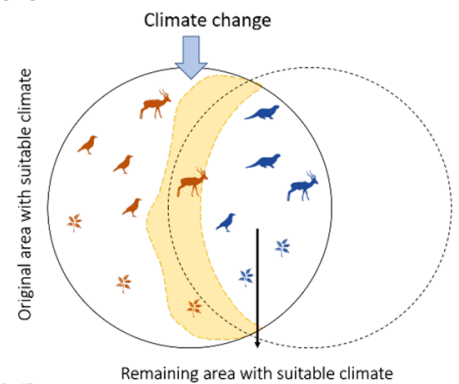

(d) Summary
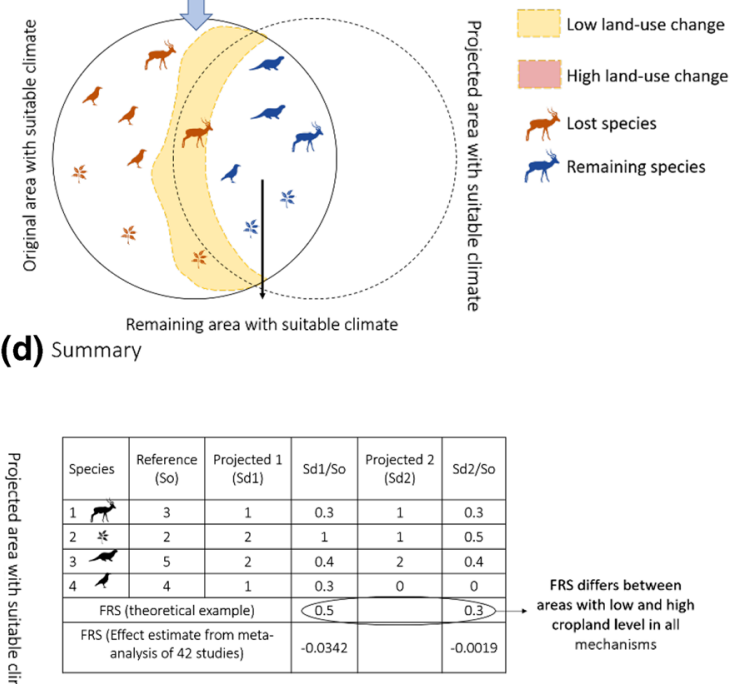

Fig. 1 Schematic illustration to indicate expected consequences of interactions on the Fraction of Remaining Species. a shows the reference situation of original species at a location; $\mathbf{b}$ shows the projected situation with low land-use change and climate change; and $\mathbf{c}$ shows the projected situation with high land-use change and climate change. Projected situations 1 and 2 show species loss (in orange) from original area with suitable climate, and remaining species (in blue) in the remaining area with suitable climate. This information is used to calculate FRS in d. Theoretically, FRS differs between projected situations 1 and 2 (i.e. 0.5 and 0.3 ) due to changed vulnerability to climate change of remained species after land-use change (mechanism 1), increased species tolerance for future land-use change (mechanism 2) and changes in extents of occurrence of species and their vulnerability to climate change (mechanisms 3 and 4). However, the estimates from the mixed-effects model indicate that FRS of areas with high cropland level (i.e. estimate $=-0.0342$ ) did not significantly differ from those areas with a low cropland level estimate $=-0.0019$ )

Table 3 Results of the mixed-random effects model for individual predictors 'global mean temperature increase' and 'cropland level' with FRS as response variable

\begin{tabular}{lrlrrrr}
\hline Fixed effects & Estimate & SE & $p$-value & $z$-value & CI (lb) & CI (ub) \\
\hline $\begin{array}{l}\text { Temperature } \\
\quad \text { antercept }\end{array}$ & & & & & & \\
$\quad$ Temperature & 0.0670 & 0.0260 & 0.0090 & 2.6290 & 0.0170 & $0.1170^{* *}$ \\
$\quad \begin{array}{l}\text { Land use } \\
\text { b (only predictor) }\end{array}$ & -0.0560 & 0.0070 & $<0.0001$ & -8.413 & -0.069 & $-0.0430 * * *$ \\
$\quad$ Intercept & -0.1524 & 0.0412 & 0.0002 & -3.7025 & -0.233 & -0.0717 \\
$\quad$ Very low & -0.0377 & 0.0534 & 0.4798 & -0.7066 & -0.1424 & 0.0669 \\
$\quad$ Low & 0.0989 & 0.0534 & 0.0637 & 1.8542 & -0.0056 & $0.2035 \bullet$ \\
$\quad$ Moderate & 0.0908 & 0.0491 & 0.0641 & 1.8512 & -0.0053 & $0.1870 \bullet$ \\
$\quad$ Very high & 0.0831 & 0.0451 & 0.0655 & 1.8420 & -0.0053 & $0.1716 \bullet$ \\
\hline
\end{tabular}

${ }^{\mathrm{a}}$ Global mean temperature increase

${ }^{\mathrm{b}}$ Cropland with the five levels (i.e. very low, low, moderate, high, and very high)

Significance codes: 0 ‘***’ 0.001 '**’ 0.01 '*’ 0.05 '? 0.1 “ 1 
change (e.g. Araujo et al. 2004; McClean et al. 2005; Thuiller et al. 2005, 2006a, b; Lawler et al. 2006; Malcolm et al. 2006; Alkemade et al. 2011; Walther and van Niekerk 2015), assessed single species responses (Bennie et al. 2013) or assessed past dispersal trends (Schwartz 1993).

Previous studies that assessed additive land-use and climate-change effects (MantykaPringle et al. 2012; Newbold 2018), indicated that changes in biodiversity likely vary spatially. For example, tropical regions are projected to experience larger losses of biodiversity under climate change (Higgins 2007; Asner et al. 2010) than temperate regions (GarciaValdes et al. 2015). Temperate regions have already undergone some of the largest biodiversity losses from land-use changes over centuries and thus the climate effect is likely small (Newbold 2018). Our analysis, however, showed that intensively managed landscapes did not change species responses to climate change. This was particularly important to verify mechanism 2 . These species responses are likely most sensitive in deserts, temperate forests and shrublands, regardless of land use (Nunez et al. 2019). This spatial variation was neglected by most studies that simultaneously assessed combined effects of these drivers in multiple land-cover types (e.g. Heubes et al. 2013; Jantz et al. 2015; Riordan et al. 2015). While most studies that assessed changes in climate and land use, found an increased combined effect (e.g. Jetz et al. 2007; Pompe et al. 2008), a few showed that the combined effect sometimes had a weak impact on biodiversity (Hoiss et al. 2013; Brown et al. 2015).

Our assessment approach of interaction effects, and particularly from mechanisms 3 and 4 , included factors, which involve large uncertainties such as species' dispersal capacities (Hellmann et al. 2016). Thus mechanisms could be operating simultaneously and potentially in opposite directions from each other, making it less likely that significant changes would be observed in the meta-analysis. Other inherent factors that affect interaction mechanisms include species adaptive capacity (Dawson et al. 2011) and the more gradual and long-term effects of climate change (Nunez et al. 2019) and changing atmospheric $\mathrm{CO}_{2}$ concentrations. Such factors also involve large uncertainties in projecting species distributions in response to climate change and need to be included when assessing interaction mechanisms. Furthermore, future assessments should also consider the physiological characteristics of species and the time lags resulting from the expected changes in both land use and climate (Hof 2021). Although future projections of land-use and climate change are challenging to create, our study serves as a starting point to introduce more elements to assess such changes and their interactions mechanisms.

The lack of integration of land-use (e.g. intensively managed areas) and climate-change effects in interaction mechanisms implies that the projected biodiversity responses probably inadequately inform biodiversity managers and policy makers on possibilities to develop appropriate biodiversity-conservation measures (de Chazal and Rounsevell 2009; Mantyka-Pringle et al. 2012, 2015; Heubes et al. 2013; Brown et al. 2015; Segan et al. 2016). This knowledge gap, however, can certainly be explored using the expected consequences to better validate interaction effects. While our study concludes that these interaction mechanisms have low significance in intensively managed areas, we do not rule out drivers interactions in other land-use types. Stronger indicators can further elucidate these mechanisms. Our study strongly supports the notion that climate and land-use changes dramatically alter biodiversity and thus improved understanding of how climate and land use-change effects interact could improve biodiversity-loss projections. Integrating these interactions effects into biodiversity-impact assessments will likely become important to develop more comprehensive and reliable strategies for biodiversity conservation and restoration. 
Supplementary Information The online version contains supplementary material available at https://doi. org/10.1007/s10531-021-02271-y.

Author contributions Both authors contributed to the study conception and design. Material preparation, data collection and analysis were performed by SN. The first draft of the manuscript was written by SN and RA commented on previous versions of the manuscript. Both authors read and approved the final manuscript.

Funding The authors would like to acknowledge the "Impacts and Risks from High-End Scenarios: Strategies for Innovative Solutions (IMPRESSIONS)" project (Grant Agreement 603416) from the EU FP7 programme for providing financial support to conduct this research.

\section{Declarations}

Conflict of interest The authors have declared that no competing interests exist.

Open Access This article is licensed under a Creative Commons Attribution 4.0 International License, which permits use, sharing, adaptation, distribution and reproduction in any medium or format, as long as you give appropriate credit to the original author(s) and the source, provide a link to the Creative Commons licence, and indicate if changes were made. The images or other third party material in this article are included in the article's Creative Commons licence, unless indicated otherwise in a credit line to the material. If material is not included in the article's Creative Commons licence and your intended use is not permitted by statutory regulation or exceeds the permitted use, you will need to obtain permission directly from the copyright holder. To view a copy of this licence, visit http://creativecommons.org/licenses/by/4.0/.

\section{References}

Alkemade R, Bakkenes M, Eickhout B (2011) Towards a general relationship between climate change and biodiversity: an example for plant species in Europe. Reg Environ Change 11:143-150

Alkemade R, van Oorschot M, Miles L, Nellemann C, Bakkenes M, ten Brink B (2009) GLOBIO3: a framework to investigate options for reducing global terrestrial biodiversity loss. Ecosystems 12:374-390

Araujo M, Cabeza M, Thuiller W, Hannah L, Williams P (2004) Would climate change drive species out of reserves? an assessment of existing reserve-selection methods. Glob Change Biol 10:1618-1626

Asner GP, Loarie SR, Heyder U (2010) Combined effects of climate and land-use change on the future of humid tropical forests. Conserv Lett 3:395-403

Bellard C, Bertelsmeier C, Leadley P, Thuiller W, Courchamp F (2012) Impacts of climate change on the future of biodiversity. Ecol Lett 15:365-377

Beltran BJ, Franklin J, Syphard AD, Regan HM, Flint LE, Flint AL (2014) Effects of climate change and urban development on the distribution and conservation of vegetation in a Mediterranean type ecosystem. Int J Geogr Inf Sci 28:1561-1589

Bennie J, Hodgson JA, Lawson CR, Holloway CTR, Roy DB, Brereton T, Thomas CD, Wilson RJ (2013) Range expansion through fragmented landscapes under a variable climate. Ecol Lett 16:921-929

Broennimann O, Thuiller W, Hughes G, Midgley GF, Alkemade J, Guisan A (2006) Do geographic distribution, niche property and life form explain plants' vulnerability to global change? Glob Change Biol 12:1079-1093

Brook BW, Sodhi NS, Bradshaw CJA (2008) Synergies among extinction drivers under global change. Trends Ecol Evol 23:453-460

Brown KA, Parks KE, Bethell CA, Johnson SE, Mulligan M (2015) Predicting plant diversity patterns in Madagascar: understanding the effects of climate and land cover change in a biodiversity hotspot. PLoS One 10:e0122721

Byrd KB, Flint LE, Alvarez P, Casey CF, Sleeter BM, Soulard CE, Flint AL, Sohl TL (2015) Integrated climate and land use change scenarios for California rangeland ecosystem services: wildlife habitat, soil carbon, and water supply. Landscape Ecol 30:729-750

Dawson TP, Jackson ST, House JI, Prentice IC, Mace GM (2011) Beyond predictions: biodiversity conservation in a changing climate. Science $332: 53-58$ 
de Chazal J, Rounsevell MDA (2009) Land-use and climate change within assessments of biodiversity change: a review. Global Environ Chang Human Policy Dimensions 19:306-315

Defourny P, Boettcher M, Bontemps S, Kirches G, Krueger O, Lamarche C, Lembrée C, Radoux J, Verheggen A (2014) Algorithm theoretical basis document for land cover climate change initiative. Eur Space Agency, 191.

Fahrig L (2003) Effects of habitat fragmentation on biodiversity. Annu Rev Ecol Evol Syst 34:487-515

Garcia-Valdes R, Svenning J-C, Zavala MA, Purves DW, Araujo MB (2015) Evaluating the combined effects of climate and land-use change on tree species distributions. J Appl Ecol 52:902-912

Guisan A, Thuiller W (2005) Predicting species distribution: offering more than simple habitat models. Ecol Lett 8:993-1009

Hannah L, Midgley G, Andelman S, Araujo M, Hughes G, Martinez-Meyer E, Pearson R, Williams P (2007) Protected area needs in a changing climate. Front Ecol Environ 5:131-138

Hellmann F, Alkemade R, Knol OM (2016) Dispersal based climate change sensitivity scores for European species. Ecol Ind 71:41-46

Heubes J, Schmidt M, Stuch B, Marquez JRG, Wittig R, Zizka G, Thiombiano A, Sinsin B, Schaldach R, Hahn K (2013) The projected impact of climate and land use change on plant diversity: an example from West Africa. J Arid Environ 96:48-54

Higgins PAT (2007) Biodiversity loss under existing land use and climate change: an illustration using northern South America. Glob Ecol Biogeogr 16:197-204

Hof C (2021) Towards more integration of physiology, dispersal and land-use change to understand the responses of species to climate change. J Expt Biol. https://doi.org/10.1242/jeb.238352

Hoiss B, Gaviria J, Leingartner A, Krauss J, Steffan-Dewenter I (2013) Combined effects of climate and management on plant diversity and pollination type in alpine grasslands. Divers Distrib 19:386-395

IPBES (2019) Summary for Policymakers of the Global Assessment Report on Biodiversity and Ecosystem Services of the Intergovernmental Science - Policy Platform on Biodiversity and Ecosystem Services. Bonn.

Jantz SM, Barker B, Brooks TM, Chini LP, Huang Q, Moore RM, Noel J, Hurtt GC (2015) Future habitat loss and extinctions driven by land-use change in biodiversity hotspots under four scenarios of climatechange mitigation. Conserv Biol 29:1122-1131

Jetz W, Wilcove D, Dobson A (2007) Projected impacts of climate and land-use change on the global diversity of birds. PLoS Biol 5:e157

Latimer CE, Zuckerberg B (2021) Habitat loss and thermal tolerances influence the sensitivity of resident bird populations to winter weather at regional scales. J Anim Ecol 90:317-329

Lawler J, White D, Neilson R, Blaustein A (2006) Predicting climate-induced range shifts: model differences and model reliability. Glob Change Biol 12:1568-1584

Malcolm J, Liu C, Neilson R, Hansen L, Hannah L (2006) Global warming and extinctions of endemic species from biodiversity hotspots. Conserv Biol 20:538-548

Mantyka-Pringle CS, Martin TG, Rhodes JR (2012) Interactions between climate and habitat loss effects on biodiversity: a systematic review and meta-analysis. Glob Change Biol 18:1239-1252

Mantyka-Pringle CS, Visconti P, Di Marco M, Martin TG, Rondinini C, Rhodes JR (2015) Climate change modifies risk of global biodiversity loss due to land-cover change. Biol Cons 187:103-111

McClean C, Lovett J, Kuper W, Hannah L, Sommer J, Barthlott W, Termansen M, Smith G, Tokamine S, Taplin J (2005) African plant diversity and climate change. Ann Mo Bot Gard 92:139-152

McGuire JL, Lawler JJ, McRae BH, Nuñez TA, Theobald DM (2016) Achieving climate connectivity in a fragmented landscape. Proc Nat Acad Sci USA 113:7195-7200

Midgley G, Hughes G, Thuiller W, Rebelo A (2006) Migration rate limitations on climate change-induced range shifts in Cape Proteaceae. Divers Distrib 12:555-562

Newbold T (2018) Future effects of climate and land-use change on terrestrial vertebrate community diversity under different scenarios. Proc R Soc Lond B 285:20180792

Nunez S, Arets E, Alkemade R, Verwer C, Leemans R (2019) Assessing the impacts of climate change on biodiversity: is below $2{ }^{\circ} \mathrm{C}$ enough? Clim Change 154:351-365

Oliver TH, Morecroft MD (2014) Interactions between climate change and land use change on biodiversity: attribution problems, risks, and opportunities. Wiley Interdiscip Rev Clim Change 5:317-335

Opdam P, Wascher D (2004) Climate change meets habitat fragmentation: linking landscape and biogeographical scale levels in research and conservation. Biol Cons 117:285-297

Pereira HM, Leadley PW, Proença V, Alkemade R, Scharlemann JPW, Fernandez-Manjarrés JF, Araújo MB, Balvanera P, Biggs R, Cheung WWL, Chini L, Cooper HD, Gilman EL, Guénette S, Hurtt GC, Huntington HP, Mace GM, Oberdorff T, Revenga C, Rodrigues P, Scholes RJ, Sumaila UR, Walpole M (2010) Scenarios for global biodiversity in the 21st century. Science 330:1496-1501 
Pompe S, Hanspach J, Badeck F, Klotz S, Thuiller W, Kuehn I (2008) Climate and land use change impacts on plant distributions in Germany. Biol Let 4:564-567

Riordan EC, Gillespie TW, Pitcher L, Pincetl SS, Jenerette GD, Pataki DE (2015) Threats of future climate change and land use to vulnerable tree species native to Southern California. Environ Conserv 42:127-138

Rondinini C, Visconti P (2015) Scenarios of large mammal loss in Europe for the 21(st) century. Conserv Biol 29:1028-1036

Sala OE, Chapin FS, Armesto JJ, Berlow E, Bloomfield J, Dirzo R, Huber-Sanwald E, Huenneke LF, Jackson RB, Kinzig A (2000) Global biodiversity scenarios for the year 2100. Science 287:1770-1774

Sales LP, Galetti M, Pires MM (2020) Climate and land-use change will lead to a faunal "savannization" on tropical rainforests. Glob Change Biol 26:7036-7044

Schwartz MW (1993) Modelling effects of habitat fragmentation on the ability of trees to respond to climatic warming. Biodivers Conserv 2:51-61

Segan DB, Murray KA, Watson JEM (2016) A global assessment of current and future biodiversity vulnerability to habitat loss-climate change interactions. Global Ecol Conserv 5:12-21

Thomas CD (2000) Dispersal and extinction in fragmented landscapes. Proc R Soc Lond B 267:139-145

Thuiller W, Albert C, Araujo MB, Berry PM, Cabeza M, Guisan A, Hickler T, Midgely GF, Paterson J, Schurr FM, Sykes MT, Zimmermann NE (2008) Predicting global change impacts on plant species' distributions: Future challenges. Perspect Plant Ecol Evol Systemat 9:137-152

Thuiller W, Broennimann O, Hughes G, Alkemade JRM, Midgley GF, Corsi F (2006a) Vulnerability of African mammals to anthropogenic climate change under conservative land transformation assumptions. Glob Change Biol 12:424-440

Thuiller W, Lavorel S, Araujo MB, Sykes MT, Prentice IC (2005) Climate change threats to plant diversity in Europe. Proc Nat Acad Sci USA 102:8245-8250

Thuiller W, Midgley GF, Hughes GO, Bomhard B, Drew G, Rutherford MC, Woodward FI (2006b) Endemic species and ecosystem sensitivity to climate change in Namibia. Glob Change Biol 12:759-776

Tittensor DP, Walpole M, Hill SLL, Boyce DG, Britten GL, Burgess ND, Butchart SHM, Leadley PW, Regan EC, Alkemade R, Baumung R, Bellard C, Bouwman L, Bowles-Newark NJ, Chenery AM, Cheung WWL, Christensen V, Cooper HD, Crowther AR, Dixon MJR, Galli A, Gaveau V, Gregory RD, Gutierrez NL, Hirsch TL, Höft R, Januchowski-Hartley SR, Karmann M, Krug CB, Leverington FJ, Loh J, Lojenga RK, Malsch K, Marques A, Morgan DHW, Mumby PJ, Newbold T, NoonanMooney K, Pagad SN, Parks BC, Pereira HM, Robertson T, Rondinini C, Santini L, Scharlemann JPW, Schindler S, Sumaila UR, Teh LSL, Van Kolck J, Visconti P, Ye Y (2014) A mid-term analysis of progress toward international biodiversity targets. Science 346:241-244

Viechtbauer W (2010) Conducting meta-analyses in R with the metafor package. J Stat Softw 36(3):1-48

Visconti P, Bakkenes M, Baisero D, Brooks T, Butchart SHM, Joppa L, Alkemade R, Di Marco M, Santini L, Hoffmann M, Maiorano L, Pressey RL, Arponen A, Boitani L, Reside AE, van Vuuren DP, Rondinini C (2015) Projecting global biodiversity indicators under future development scenarios. Conserv Lett 9:5-13

Vos CC, Berry P, Opdam P, Baveco H, Nijhof B, O’Hanley J, Bell C, Kuipers H (2008) Adapting landscapes to climate change: examples of climate-proof ecosystem networks and priority adaptation zones. J Appl Ecol 45:1722-1731

Walther B, van Niekerk A (2015) Effects of climate change on species turnover and body mass frequency distributions of South African bird communities. Afr J Ecol 53:25-35

Wiens J, Stralberg D, Jongsomjit D, Howell C, Snyder M (2009) Niches, models, and climate change: Assessing the assumptions and uncertainties. Proc Nat Acad Sci USA 106:19729-19736

Publisher's Note Springer Nature remains neutral with regard to jurisdictional claims in published maps and institutional affiliations.

\section{Authors and Affiliations}

\section{Sarahi Nunez ${ }^{1}$ (D) Rob Alkemade ${ }^{1,2}$}

1 Environmental Systems Analysis Group, Wageningen University and Research, PO Box 47, 6700 AA Wageningen, The Netherlands

2 PBL-Netherlands Environmental Assessment Agency, PO Box 30314, 2500 GH The Hague, The Netherlands 